Article

\title{
Strengthening Al-Zn-Mg Alloys via Ultra-Fine Lamella Structures Containing a High Density of Dislocations and Clusters
}

\author{
Yonggui Qin ${ }^{1}$, Sicong Lin ${ }^{1}$, Shenbao Jin ${ }^{1, *}$ and Jizi Liu ${ }^{1,2,3, *(\mathbb{D}}$ \\ 1 Materials Characterization \& Research Center, School of Materials Science and Engineering, \\ Nanjing University of Science and Technology, Nanjing 210094, China; 116116001365@njust.edu.cn (Y.Q.); \\ 117116022355@njust.edu.cn (S.L.) \\ 2 State Key Laboratory of Advanced Design and Manufacturing for Vehicle Body, Hunan University, \\ Changsha 410082, China \\ 3 Nano and Heterogeneous Materials Center, School of Materials Science and Engineering, \\ Nanjing University of Science and Technology, Nanjing 210094, China \\ * Correspondence: jinshenbao@njust.edu.cn (S.J.); jzliu@njust.edu.cn (J.L.); Tel.: +86-258-430-3406 (S.J. \& J.L.)
}

Received: 15 December 2018; Accepted: 24 January 2019; Published: 28 January 2019

\begin{abstract}
A new method of thermo-mechanical processing has been designed by introducing pre-aging before general cold rolling for an $\mathrm{Al}-\mathrm{Zn}-\mathrm{Mg}$ alloy. This process results in an increase of $200 \mathrm{MPa}$ in yield strength compared to that of the peak-aged samples. The microstructures were examined by transmission electron microscope and X-ray diffraction. It has been found that the enhanced strength is mainly contributed to by ultra-fine lamella structures containing a high density of dislocations pinned by nanoprecipitates. Extra strength is provided by the "interlocking" of precipitates and dislocations. Fractographic features analysis shows that crack propagation along the interface of the lamella structures is the direct reason for resulting in fracture, due to intra-granular strength exceeding grain boundary cohesion.
\end{abstract}

Keywords: Al-Zn-Mg alloy; UFG; lamella structure; thermo-mechanical processing; dislocation; precipitate

\section{Introduction}

$\mathrm{Al}-\mathrm{Zn}-\mathrm{Mg}$ alloys are widely used as structural materials in aerospace and other transportation applications for their high strength and low density [1]. Aging hardening is an effective approach to strengthen $\mathrm{Al}-\mathrm{Zn}-\mathrm{Mg}$ alloys [2-7] via a high density of nanosized precipitates inhibiting the dislocation motion. Strain-hardening is another popular strengthening mechanism employed in $\mathrm{Al}$ alloys. The strengthening effect from a single mechanism is limited; researches have tried to explore the combined effect of these strengthening mechanisms such as dislocations and precipitations [8-13]. Thus, thermo-mechanical processes (TMPs) have been significantly developed. The strength has been improved dramatically by conventional TMPs in Al-Mg-Si alloys and Al-Cu-Mg alloys, but little in $\mathrm{Al}-\mathrm{Zn}-\mathrm{Mg}$ alloys, compared to their peak-aged counterparts [14-18].

Still, Zhao et al. found that the coupling of dislocations and precipitates offers a pleasant surprise in microstructures [15,19-21], i.e., nanosized grains, which provide extra strength for 7075 alloy (one of the Al-Zn-Mg alloys). In these works, the thermo-mechanical processes used were designed as solid solution treatment + severely plastic deformation (SPD) + aging, promoting heterogeneous nucleation of precipitates employing dislocations as the nucleation site, meanwhile resulting in grain refinement via precipitates pinning the sub-grain boundary. Although it will be difficult to explore these approaches commercially, these works provide a new strategy for strengthening $\mathrm{Al}-\mathrm{Zn}-\mathrm{Mg}$ alloys, 
which also reminds us there is still room for improvement in conventional TMPs, if knowledge about the coupling of precipitates and dislocations is upgraded.

In this work, an Al-Zn-Mg alloy (7N01) with the lowest $\mathrm{Zn}$ content in all commercial Al-Zn-Mg series, widely applied as a structure material in high-speed trains, was employed to investigate the coupling of precipitates and dislocations. However, this time, types of sheared precipitates $\left(\mathrm{GP}_{\eta^{\prime}}\right.$ zones [2,3]) by dislocations were introduced before conventional deformation (cold rolling), in other words, aging was ahead of deformation. A significant improvement was achieved in the strength of 7N01 alloy, which was contributed to by ultra-fine lamella grains, phase transformation and a high density of evenly distributed dislocations.

\section{Experimental Materials and Procedures}

A commercial hot-rolled plate, with a major composition of $4.38 w t . \% \mathrm{Zn}-1.35 w t . \% \mathrm{Mg}$-balance $\mathrm{Al}$, was employed in this investigation. These plates were solution-treated at $475{ }^{\circ} \mathrm{C}$ for $1.5 \mathrm{~h}$, then quenched in water to the ambient temperature. The quenched samples were immediately aged at $120{ }^{\circ} \mathrm{C}$ for $24 \mathrm{~h}$ (T6-treatment). Part of the aged samples were subsequently cold-rolled at room temperature to a total thickness reduction of $\sim 60 \%$, named as AR (aging-rolling) sample. For comparison, the quenched samples were rolled at the same condition as the AR sample, termed as the QR (quenching-rolling) sample, similar to the NS sample prepared by Zhao et al. [20].

Specimens with a gage length of $5 \mathrm{~mm}$, a thickness of $1.8 \mathrm{~mm}$ and a width of $2 \mathrm{~mm}$ were used for tensile testing, which was carried out at ambient temperature and at a constant strain rate of $1 \times 10^{-3} \mathrm{~s}^{-1}$ on a Shimadzu AGS-X universal tester (SHIMADZU, Kyoto, Japan). The specimen axis was aligned with the direction of rolling. The values of strength and ductility were taken from an average of three specimens. The yield strength was estimated by the stress at $0.2 \%$ plastic strain. The microstructures were observed using an FEI Titan G2 60-300 transmission electron microscope (TEM) (Thermo Fisher Scientific Inc., Waltham, MA, USA) with a spherical aberration corrector under the objective lens operated at $300 \mathrm{kV}$. TEM specimens were prepared using twin-jet electro-polishing with a solution of $30 \%$ nitric acid and $70 \%$ methanol under a relatively constant temperature between $-20^{\circ} \mathrm{C}$ and $-30^{\circ} \mathrm{C}$. XRD measurements were taken on a Bruker-AXS D8 Advance X-ray diffractometer (Bruker, Karlsruhe, Germany) equipped with a $\mathrm{Cu}$ target operating at $1.8 \mathrm{~kW}$. $\theta-2 \theta$ step scans were taken to record the XRD patterns at room temperature. The scanning step was $0.02^{\circ}$ and the scanning rate was $0.6 \mathrm{~s}$ per step. The scanning area was about $2 \mathrm{~mm} \times 10 \mathrm{~mm}$.

\section{Experimental Results}

Figure 1 shows the engineering stress-strain curves of the T6, QR and AR samples. The tensile yield strength (marked by solid circles on curves) and ultimate strength of the AR sample are $497 \mathrm{MPa}$ and $527 \mathrm{MPa}$, respectively, which are about $67 \%$ and $45 \%$ higher than those of the T6-treated sample (297 MPa and $363 \mathrm{MPa}$ ). The tensile yield strength and ultimate strength of the QR sample are $422 \mathrm{MPa}$ and $466 \mathrm{MPa}$, respectively, $42 \%$ and $28 \%$ higher than those of the T6 treated sample. In comparison to the $\mathrm{QR}$ sample, the yield strength and ultimate strength of the AR sample are increased by about $75 \mathrm{MPa}$ and $61 \mathrm{MPa}$, respectively. The uniform elongation (marked by solid squares on curves) and the elongation to failure of the AR sample are $3.5 \%$ and $7.7 \%$, respectively. Obviously, they are significantly lower than those of the T6 treated sample (11.9\% for uniform elongation and $22.5 \%$ for elongation to failure), and slightly lower than those of the QR sample (5.8\% for uniform elongation and $10.1 \%$ for elongation to failure). This decrease in tensile ductility is typical for cold-worked metals [22,23], but the extremely high strength is very worthwhile to understand the strengthening mechanism. The strength of the QR sample is higher than that of the T6 sample, attributing to the fine grain size and a high density of dislocations reported by Zhao et al. [20]. The strength of AR samples is even higher than that of the QR sample, the over strength must not be thought of simply as the contribution of work-hardening or precipitation-strengthening. 


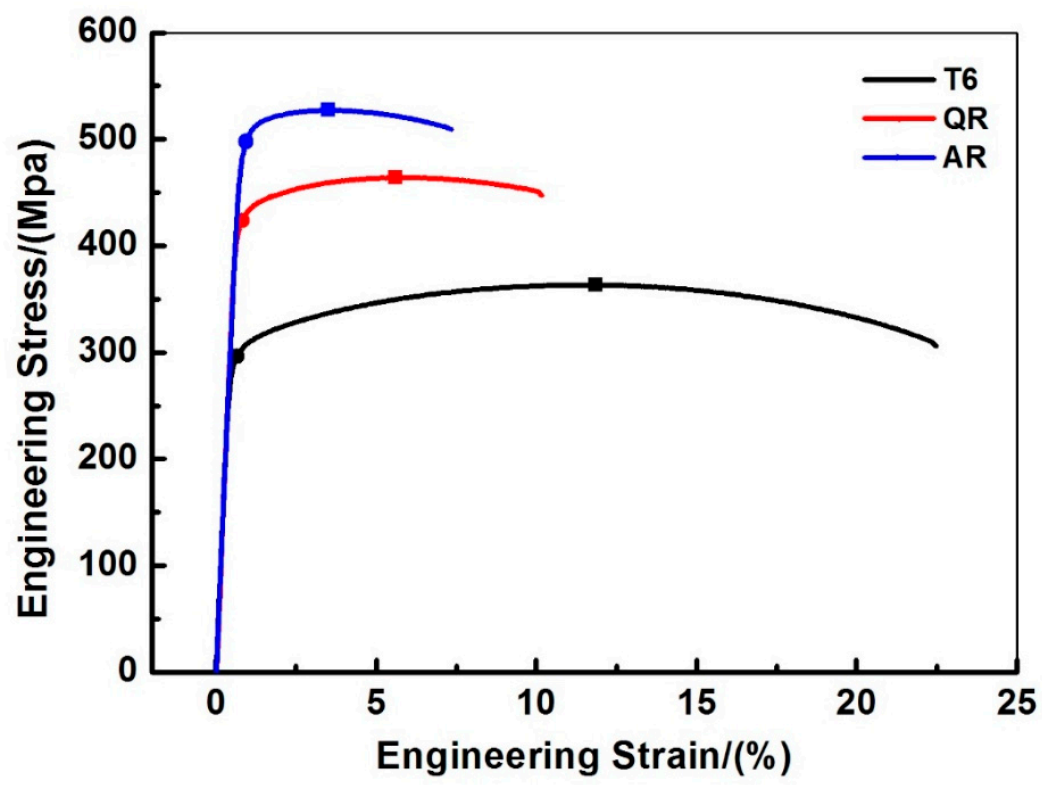

Figure 1. The stress-stain curves of samples subjected to T6 treatment or thermos-mechanical processing (AR and QR).

Figure 2 shows the representative bright-field and corresponding dark-field TEM images of the T6-treated sample and AR sample. In the T6-sample, the microstructure consists of elongated micron-sized coarse grains and sub-micro subgrains; as shown in Figure 2a,b, the average grain diameter of the T6-sample is about $1822 \pm 150 \mathrm{~nm}$. In the AR sample, lamella structures are primarily observed in Figure 2c, with a mean thickness of $137 \pm 20 \mathrm{~nm}$ and a mean length of $2000 \pm 270 \mathrm{~nm}$. Averaging the mean length and the mean thickness of the elongated grains yields an estimate for the mean grain diameter of $590 \pm 55 \mathrm{~nm}$. Figure $2 \mathrm{~d}$ is the corresponding dark-field TEM micrograph and shows more clearly the subgrain morphologies; the slight contrast difference within lamella structures was caused by small orientation variations due to serious lattice distortion introduced by cold rolling. The selected area diffraction pattern with $<112>$ zone axis inserted in Figure $2 c$, from a $3 \mu \mathrm{m}$ diameter area of an AR sample, suggests that the grain boundaries are mostly low-angle type. The diffraction patterns were distorted into discontinuous rings, revealing a refined structure, but the misorientations were not large enough to yield continuous rings. Figure 3 shows the TEM micrographs inside a grain of the T6-treated sample and AR sample. As shown, a few of the dislocation walls or dislocation tangles are found in the T6-treated sample, while a high density of dislocations are observed in the AR sample. Little dislocation tangle (dislocation wall, dislocation cell) is observed in the AR sample; the evenly distributed dislocation morphologies indicate that the dislocation motion of cross slip is inhibited effectively by pre-existing nanoprecipitates during cold rolling. 


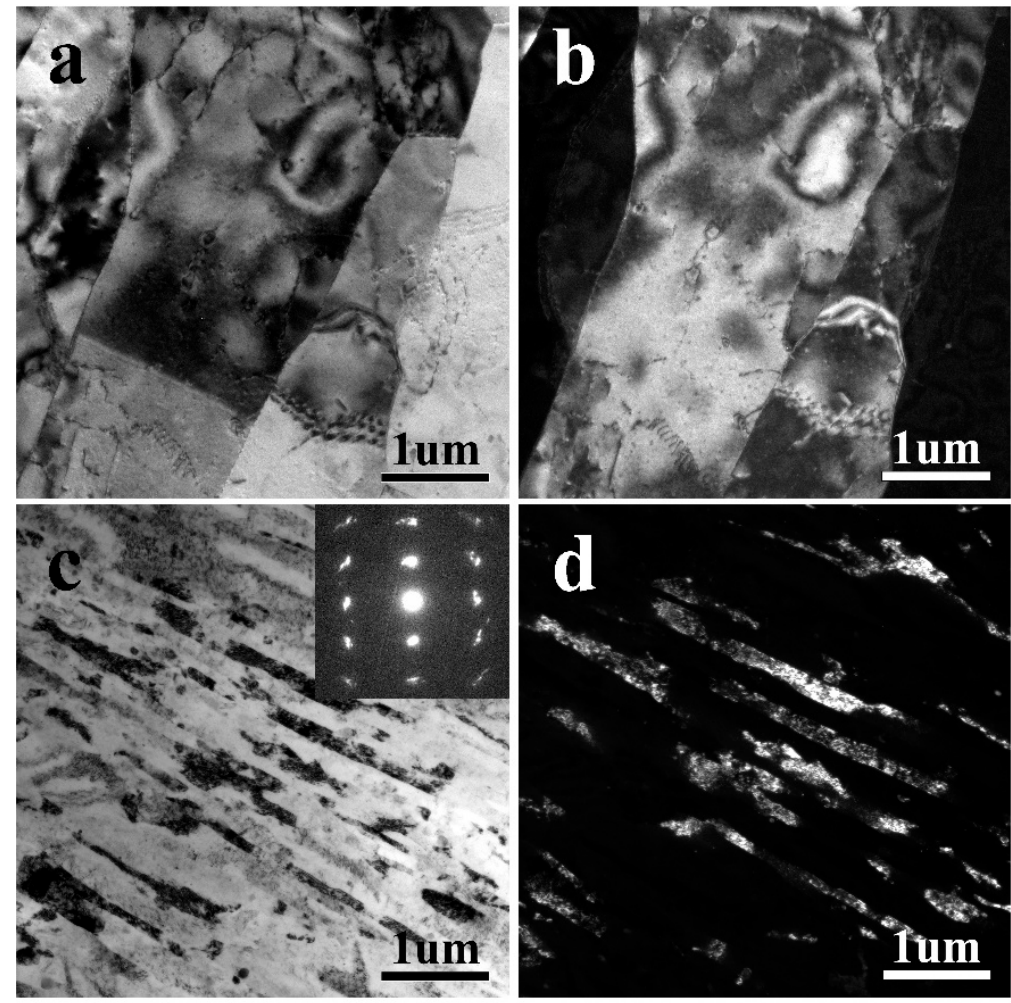

Figure 2. The bright-field $(\mathbf{a}, \mathbf{c})$ or dark-field $(\mathbf{b}, \mathbf{d})$ TEM images of grains in the T6-treated sample $(\mathbf{a}, \mathbf{b})$ or TMP-treated sample $(\mathbf{c}, \mathbf{d})$.

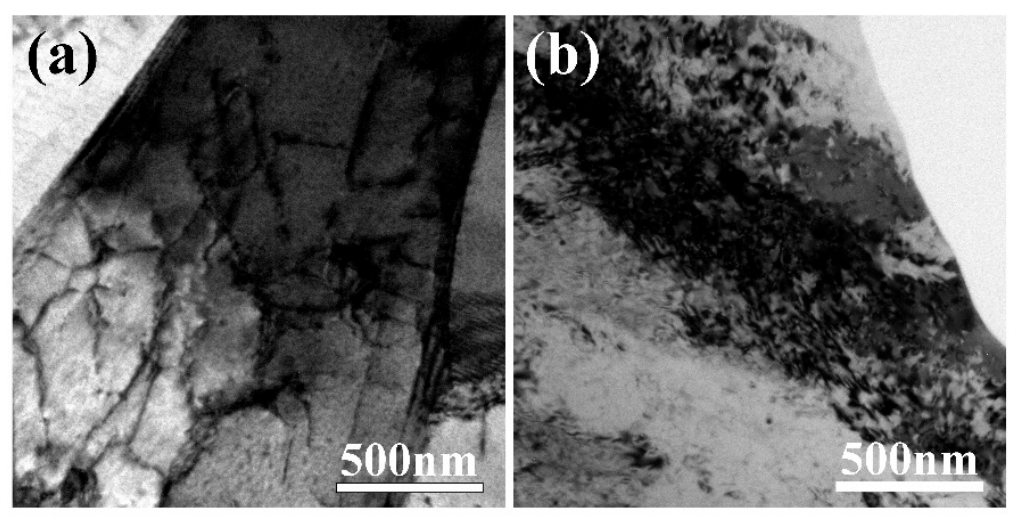

Figure 3. The morphology of dislocations in the T6-treated sample (a) or AR sample (b).

The XRD patterns for T6-treated and AR samples are displayed in Figure 4a, where the XRD peaks for precipitates are very weak and embedded in the background. The grain diameter $(d)$ and microstrain $(\varepsilon)$ of the bulk samples were calculated from the XRD peak broadening $\left(\delta_{\text {hkl }}\right)$ for the matrix, using the Williamson-Hall method [24]. It assumes that $\delta_{\mathrm{hkl}}$ consists of grain refinement broadening and strain broadening, which is given by:

$$
\delta_{\mathrm{hkl}} \cdot \cos \theta_{\mathrm{hkl}}=K \lambda / d+\varepsilon \cdot \sin \theta_{\mathrm{hkl}}
$$

where $\lambda(=1.54 \AA)$ is the wavelength of $\mathrm{Cu} K \alpha$ radiation, $K$ is a constant $(\sim 0.9)$ and $\theta_{\text {hkl }}$ is the Bragg angle. The values of $d$ can be found above, and $\varepsilon(=0.01036$ for AR sample and 0.00723 for T6 sample) 
were obtained from the slope of the fitted curve in Figure $4 \mathrm{~b}$. The dislocation density $(\rho)$ can be deduced by $d$ and $\varepsilon$ [21]:

$$
\rho=2 \sqrt{3} \varepsilon / d b
$$

where $b=0.286 \mathrm{~nm}$ is the magnitude of the Burgers vector for Al. The dislocation density for T6-treated and AR samples are calculated to be $4.81 \times 10^{13}, 2.13 \times 10^{14} \mathrm{~m}^{-2}$, respectively. Obviously, the dislocation density in the AR sample is much higher than that in the T6-treated sample, which is in good agreement with the TEM results.
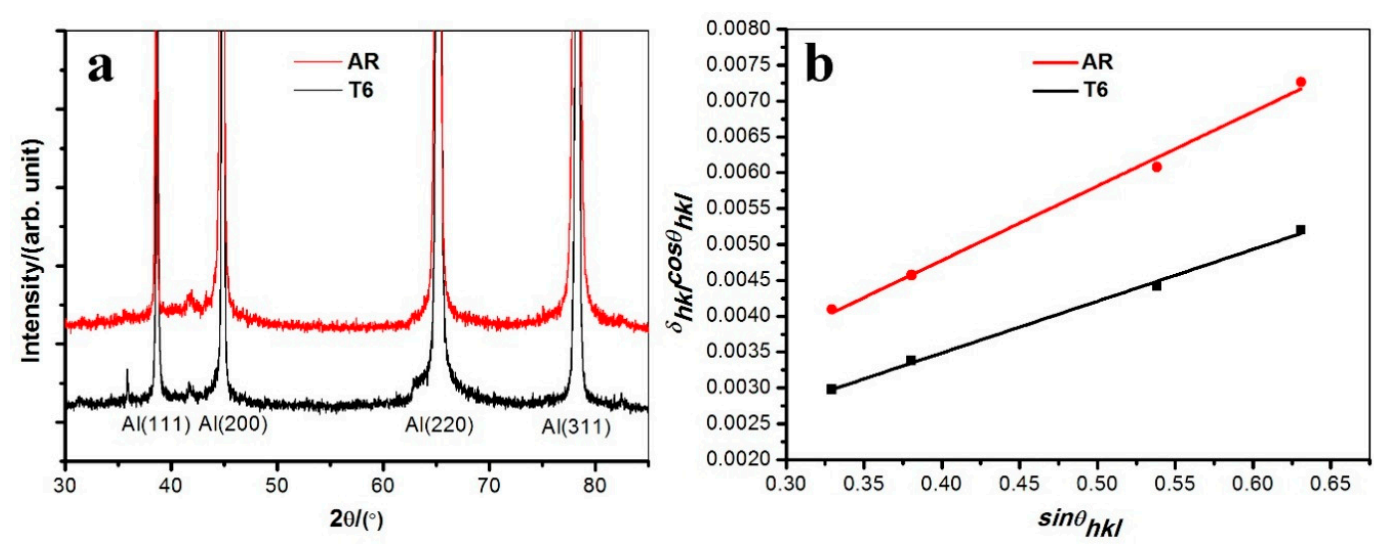

Figure 4. (a) comparison of XRD peaks of the T6-treated and AR samples, (b) plotting $\delta \cos \theta$ vs. $\sin \theta$ and performing a linear regression analysis.

Figure 5a shows typical high-angle annular dark-field scanning transmission electron microscopy (HAADF-STEM) image of a conventional T6-treated sample, showing a high density of nanosized precipitates. These precipitates are disc-like $\mathrm{GP}_{\eta^{\prime}}$ zones, as shown in the high-resolution HAADF-STEM image (Figure 5c), consisting of Zn-rich atomic layers parallel to $\{111\}$ Al-planes, and so brighter than the matrix. $\mathrm{GP}_{\eta^{\prime}}$ zones as well as the nuclei of $\eta^{\prime}$ precipitates are metastable, the latter will evolve into a stable laves phase $\left(\mathrm{MgZn}_{2}\right)$ finally during artificial aging. Figure $5 \mathrm{~b}$ displays the morphology and distribution of precipitates in AR samples. These precipitates are distributed homogenously in the grain volume and are smaller than those in the T6-treated sample in size. Obviously, pre-existing $\mathrm{GP}_{\eta^{\prime}}$ zones are fully coherent and easily sheared by sliding dislocations during cold rolling, resulting in a smaller volume and a near-spherical shape, as shown in Figure $5 \mathrm{~b}$ and d. Also, composition redistribution within precipitates are caused by moving dislocations, which are suggested by the inhomogenous contrast in the interior of precipitates (Figure $5 \mathrm{~d}$ ) instead of the homogenous contrast in $\mathrm{GP}_{\eta^{\prime}}$ zones (Figure 5c). Here, the Z-contrast of the HAADF-STEM image can be used to explain the Zn distribution, i.e., brighter area means higher $\mathrm{Zn}$-inclusion, and vice versa. The ordered structure of precipitates has been destroyed by dislocation shearing; as shown in Figure $5 d$, no repeated periodic cells can be extracted, so they are termed as nanoclusters. Precipitate change is caused by moving dislocations; in the meantime, dislocations are "locked" by precipitates; as shown in Figure 5b, dislocations connect precipitates and no dislocation tangle occurs. 


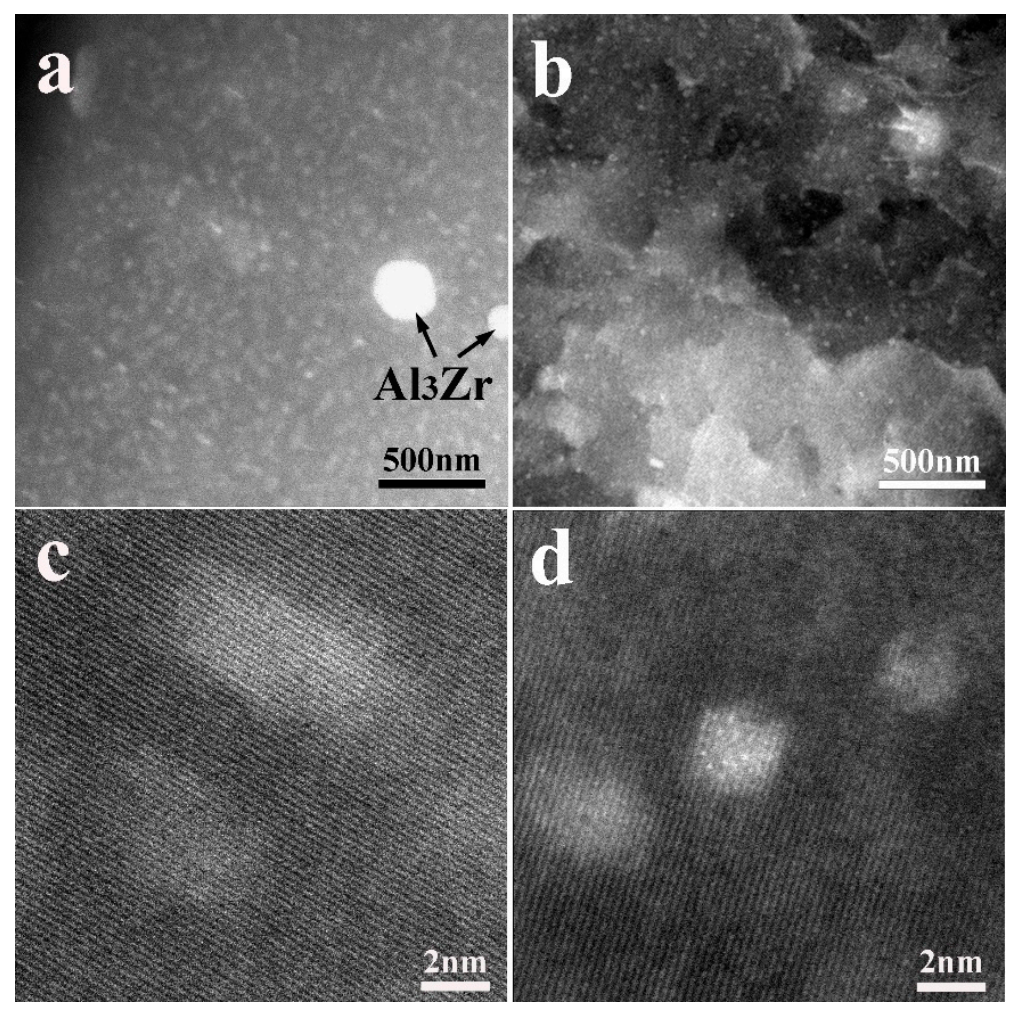

Figure 5. HAADF-STEM images showing precipitates in the T6-treated sample (a,c) and AR sample $(\mathbf{b}, \mathbf{d})$. Images were obtained under conditions with $\mathrm{Z}$ contrast using HAADF detector, along $\langle 112\rangle_{\mathrm{Al}}$ zone axis.

\section{Discussion}

\subsection{Mechanical Properties and Strengthening Mechanism}

The strength of the AR sample is significantly higher (200 MPa) than those of the T6-treated counterpart, indicating that it is possible to add the strengthening effect from cold rolling to that from the precipitation hardening. The over strength may be attributed to: (i) dislocation strengthening and (ii) grain refinement strengthening. The grain-refinement strengthening is generally described by a Hall-Petch relationship:

$$
\Delta \sigma_{0.2}=\sigma_{0}+k d^{-1 / 2}
$$

where $\sigma_{0.2}$ is the yield strength, $\sigma_{0}$ is the friction stress, $k$ is a constant (approximately $\sim 0.12 \mathrm{MPa} / \sqrt{\mathrm{m}}$ for T6-treated Al-Zn-Mg sample [9]), and d is the average grain diameter. Thus, it is revealed that $67 \mathrm{MPa}$ of the improved $200 \mathrm{MPa}$ yield strength is contributed to by grain refinement of the AR sample, in comparison to the T6 sample.

The Bailey-Hirsch relationship was applied to estimate the contribution from the residual dislocations to strengthening [13]:

$$
\Delta \sigma_{\mathrm{d}}=M \alpha G b \rho
$$

where $M$ is the mean orientation factor (=3.06 for fcc polycrystalline matrix), $\alpha$ is a constant $(=0.2$ for fcc metals) and $G$ is the shear modulus ( $=26.9 \mathrm{GPa}$ for Al-Zn-Mg alloys). The strength increment caused by dislocations is calculated to be $\sim 33 \mathrm{MPa}$ and $\sim 69 \mathrm{MPa}$ for the T6-treated and AR sample, respectively. Thus, there is $36 \mathrm{MPa}$ of the improved $200 \mathrm{MPa}$ yield strength which is contributed to by strain hardening for the AR sample, in comparison to the T6 sample.

Obviously, the yield strength of the AR sample ( $497 \mathrm{MPa})$ is not a simple sum of dislocation strengthening (36 MPa), grain-refinement strengthening (67 MPa) and yield strength of the T6-treated sample (297 MPa). Part of the strength ( $97 \mathrm{MPa})$ is from the "interlocking" of dislocations and clusters, 
because the dislocations from rolling have been "locked" by clusters, resulting in more force needed to make them move while being tensile. In other words, clusters with built-in dislocations might be more resistant to moving dislocations than fully-coherent $\mathrm{GP}_{\eta^{\prime}}$ zones.

\subsection{Tensile Fracture Analysis}

The tensile tests show that the AR sample (3.5\%) has much lower ductility than the T6-treated sample $(11.9 \%)$. Fractography was performed to explain the tensile ductility trends on the basis of fracture mechanisms. Figure 6a shows the transgranular ductile fracture of the T6-treated sample. The ductile voids here are very small due to the nanosized precipitates in the T6-treated sample. A large number of coarse voids along the interfaces between the lamella structures are observed on the fracture surface of the AR sample (Figure 6b), suggesting intergranular cracking, which is probably due to a high density of dislocations sticking at the boundaries after rolling.

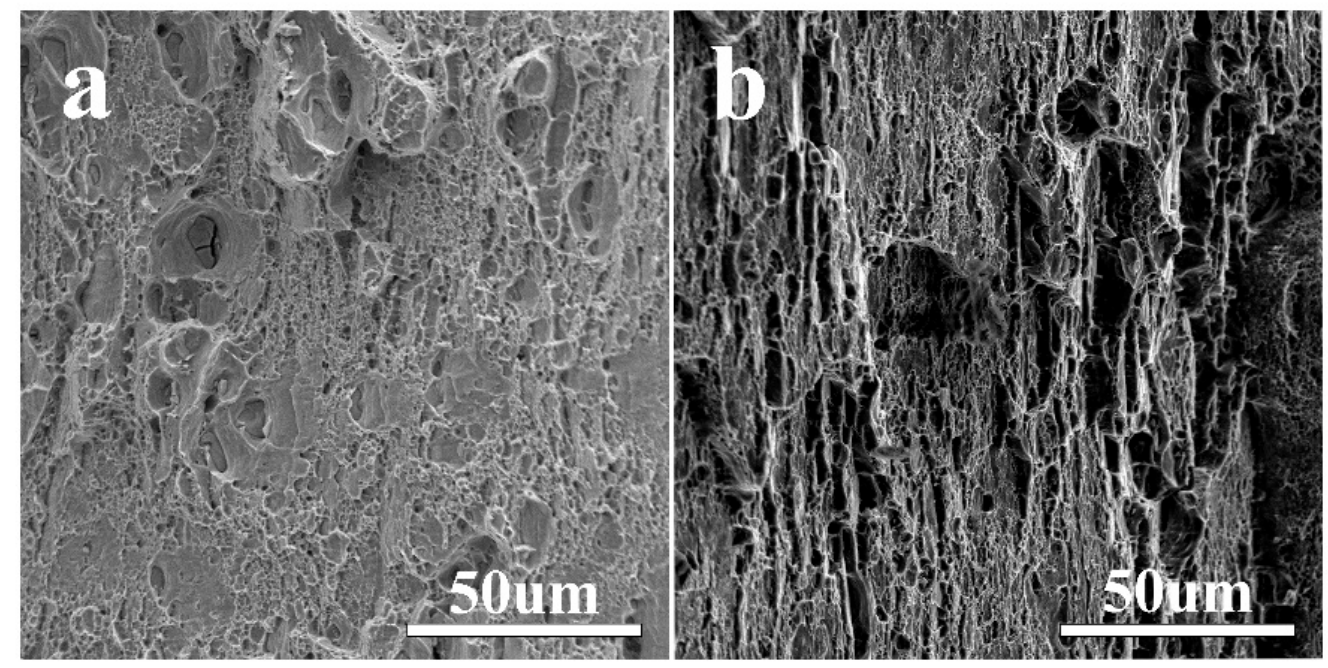

Figure 6. Fractographs of tensile fracture in the T6-treated sample (a) and AR sample (b).

\section{Conclusions}

In this study, we have developed a new process to achieve super-high strength of an Al- $\mathrm{Zn}-\mathrm{Mg}$ alloy, exceeding $200 \mathrm{MPa}$ in yield strength compared with the T6-treated sample. Unlike previous work, we purposely retained a large number of nanoprecipitates after T6 treatment, which is useful for the generation of a uniformly-distributed, high-density of dislocations during the subsequent cold rolling at room temperature, via the inhibition of dislocation cross slip. The yield strength of the AR sample is higher than the simple sum of precipitation strengthening, strain hardening and grain-refinement strengthening; the extra strength is contributed to by the "interlocking" of dislocations and precipitates. Fracture analysis indicated that the cracks initiate at the interface of the lamella grains, which is probably due to a mass of dislocations sticking at the interfaces.

Author Contributions: Conceptualization, J.L. and S.J.; Methodology, J.L. and Y.Q.; Validation, Y.Q., J.L. and S.L.; Formal analysis, J.L.; Investigation, Y.Q., S.L. and S.J.; Resources, J.L.; Data curation, Y.Q. and S.L.; Writing-Original draft preparation, Y.Q., S.L. and J.L.; Writing-Review and editing, J.L.; Supervision, J.L.; Project Administration, J.L.; Funding Acquisition, J.L.

Funding: This work was funded by the National Key R\&D Program of China (No. 2017YFA0204403), the National Natural Science Foundation of China (No. 51301064), the open fund (No. 31715009) supported by State Key Laboratory of Advanced Design and Manufacturing for Vehicle Body at Hunan University, the Fundamental Research Funds for the Central Universities (No. 30918011341).

Acknowledgments: All TEM experiments were performed at the Materials Characterization and Research Center of Nanjing University of Science and Technology.

Conflicts of Interest: The authors declare no conflict of interest. 


\section{References}

1. Williams, J.C.; Starke, E.A. Progress in structural materials for aerospace systems 11 The Golden Jubilee Issue-Selected topics in Materials Science and Engineering: Past, Present and Future, edited by S. Suresh. Acta Mater. 2003, 51, 5775-5799. [CrossRef]

2. Liu, J.Z.; Chen, J.H.; Yuan, D.W.; Wu, C.L.; Zhu, J.; Cheng, Z.Y. Fine precipitation scenarios of $\mathrm{AlZnMg}(\mathrm{Cu})$ alloys revealed by advanced atomic-resolution electron microscopy study Part I: Structure determination of the precipitates in $\operatorname{AlZnMg}(\mathrm{Cu})$ alloys. Mater. Charact. 2015, 99, 277-286. [CrossRef]

3. Liu, J.Z.; Chen, J.H.; Liu, Z.R.; Wu, C.L. Fine precipitation scenarios of $\operatorname{AlZnMg}(\mathrm{Cu})$ alloys revealed by advanced atomic-resolution electron microscopy study Part II: Fine precipitation scenarios in $\operatorname{Al} \mathrm{ZnMg}(\mathrm{Cu})$ alloys. Mater. Charact. 2015, 99, 142-149. [CrossRef]

4. Liu, J.Z.; Chen, J.H.; Yang, X.B.; Ren, S.; Wu, C.L.; Xu, H.Y.; Zou, J. Revisiting the precipitation sequence in Al-Zn-Mg-based alloys by high-resolution transmission electron microscopy. Scr. Mater. 2010, 63, 1061-1064. [CrossRef]

5. Sha, G.; Cerezo, A. Early-stage precipitation in Al-Zn-Mg-Cu alloy (7050). Acta Mater. 2004, 52, $4503-4516$. [CrossRef]

6. Macchi, C.E.; Somoza, A.; Dupasquier, A.; Polmear, I.J. Secondary precipitation in Al-Zn-Mg-(Ag) alloys. Acta Mater. 2003, 51, 5151-5158. [CrossRef]

7. Berg, L.K.; Gjønnes, J.; Hansen, V.; Li, X.Z.; Knutson-Wedel, M.; Waterloo, G.; Schryvers, D.; Wallenberg, L.R. GP-zones in Al-Zn-Mg alloys and their role in artificial aging. Acta Mater. 2001, 49, 3443-3451. [CrossRef]

8. Ma, K.; Hu, T.; Yang, H.; Topping, T.; Yousefiani, A.; Lavernia, E.J.; Schoenung, J.M. Coupling of dislocations and precipitates: Impact on the mechanical behavior of ultrafine grained Al-Zn-Mg alloys. Acta Mater. 2016, 103, 153-164. [CrossRef]

9. Ma, K.; Wen, H.; Hu, T.; Topping, T.D.; Isheim, D.; Seidman, D.N.; Lavernia, E.J.; Schoenung, J.M. Mechanical behavior and strengthening mechanisms in ultrafine grain precipitation-strengthened aluminum alloy. Acta Mater. 2014, 62, 141-155. [CrossRef]

10. Hu, T.; Ma, K.; Topping, T.D.; Schoenung, J.M.; Lavernia, E.J. Precipitation phenomena in an ultrafine-grained Al alloy. Acta Mater. 2013, 61, 2163-2178. [CrossRef]

11. Han, Y.S.; Hong, S.H. The effects of thermo-mechanical treatments on superplasticity of Fe-24Cr-7Ni-3Mo-0.14N duplex stainless steel. Scr. Mater. 1997, 36, 557-563. [CrossRef]

12. Wert, J.A.; Paton, N.E.; Hamilton, C.H.; Mahoney, M.W. Grain refinement in 7075 aluminum by thermomechanical processing. Metall. Trans. A. 1981, 12, 1267-1276. [CrossRef]

13. Bailey, J.E.; Hirsch, P.B. The dislocation distribution, flow stress, and stored energy in cold-worked polycrystalline silver. Philos. Mag. 1960, 5, 485-497. [CrossRef]

14. Panigrahi, S.K.; Jayaganthan, R. A study on the mechanical properties of cryorolled Al-Mg-Si alloy. Mater Sci. Eng. A. 2008, 480, 299-305. [CrossRef]

15. Cheng, S.; Zhao, Y.H.; Zhu, Y.T.; Ma, E. Optimizing the strength and ductility of fine structured $2024 \mathrm{Al}$ alloy by nano-precipitation. Acta Mater. 2007, 55, 5822-5832. [CrossRef]

16. Tajally, M.; Emadoddin, E. Mechanical and anisotropic behaviors of 7075 aluminum alloy sheets. Mater. Des. 2011, 32, 1594-1599. [CrossRef]

17. Huang, L.P.; Chen, K.H.; Li, S.; Song, M. Influence of high-temperature pre-precipitation on local corrosion behaviors of Al-Zn-Mg alloy. Scr. Mater. 2007, 56, 305-308. [CrossRef]

18. Tash, M.; Alkahtani, S. Effect of thermo-mechanical treatment (TMT) on hardness of heat-treated Al-Mg-Si (6082) alloys: Experimental correlation using (DOE) method. Appl. Mech. Mater. 2013, 376, 163-172. [CrossRef]

19. Zhao, Y.; Zhu, Y.; Lavernia, E.J. Strategies for Improving Tensile Ductility of Bulk Nanostructured Materials. Adv. Eng. Mater. 2010, 12, 769-778. [CrossRef]

20. Zhao, Y.H.; Liao, X.Z.; Cheng, S.; Ma, E.; Zhu, Y.T. Simultaneously Increasing the Ductility and Strength of Nanostructured Alloys. Adv.Mater. 2006, 18, 2280-2283. [CrossRef]

21. Zhao, Y.H.; Liao, X.Z.; Jin, Z.; Valiev, R.Z.; Zhu, Y.T. Microstructures and mechanical properties of ultrafine grained $7075 \mathrm{Al}$ alloy processed by ECAP and their evolutions during annealing. Acta Mater. 2004, 52, 4589-4599. [CrossRef] 
22. Huang, Y.J.; Chen, Z.G.; Zheng, Z.Q. A conventional thermo-mechanical process of Al-Cu-Mg alloy for increasing ductility while maintaining high strength. Scr. Mater. 2011, 64, 382-385. [CrossRef]

23. Horita, Z.; Fujinami, T.; Nemoto, M.; Langdon, T.G. Improvement of mechanical properties for $\mathrm{Al}$ alloys using equal-channel angular pressing. J. Mater. Process. Technol. 2001, 117, 288-292. [CrossRef]

24. Williamson, G.K.; Hall, W.H. X-ray line broadening from filed aluminium and wolfram. Acta Metall. 1953, 1, 22-31. [CrossRef] 